\section{Thermal characterisation of Bronze Age hearths from the cave of Les Fraux (Dordogne, France) by thermoluminescence and magnetic susceptibility techniques}

\author{
Aurélie Brodard, ${ }^{1}$ Pierre Guibert, ${ }^{1}$ \\ François Lévêque, ${ }^{2}$ Vivien Mathé, ${ }^{2}$ \\ Albane Burens, ${ }^{3}$ Laurent Carozza ${ }^{3}$
}

'Université de Bordeaux 3 - CNRS, IRAMATCRP2A, UMR 5060, Maison de l'Archéologie, 33607 Pessac; ${ }^{2}$ Université de La Rochelle - CNRS, LIENSs, UMR 6250, 17000 La Rochelle; ${ }^{3}$ Université de Toulouse le Mirail - CNRS, GEODE, UMR 5602, Maison de la Recherche, 31058 Toulouse, France

\section{Abstract}

In the cave of Les Fraux (Dordogne, France) numerous traces of fires are visible in the galleries. A multidisciplinary investigation was carried out to study these fires. This paper presents the methodology applied for the hearth study. It is based on the examination of the thermoluminescence (TL) of quartz and the magnetic susceptibility of iron oxides. First of all, magnetic susceptibility was measured on the surface of hearths. Based on both susceptibility mapping and visible sediment characteristics, small sediment samples (1-2 g) were taken. Subsequently, quartz grains were extracted from the sediment samples. Fourteen thermal references were obtained by heating (from 200 to $650^{\circ} \mathrm{C}$ ) fractions of the pristine unfired cave sediment. Comparing the TL signal of anciently heated quartz to the reference samples allowed to obtain the maximum equivalent temperature attained for each sample extracted from ancient fires. Consequently, the correspondence between magnetic susceptibility and temperature allowed for the reconstruction of a paleotemperature map of the study area. This research provides information about fire intensity in the cave, which can help to understand its function.

\section{Introduction}

Accidentally discovered in 1989, the cave of Les Fraux is located at Saint-Martin-de-
Fressengeas, Dordogne, France (coordinates: $\mathrm{x}=484.030 \mathrm{y}=2050.670 \mathrm{z}=240 \mathrm{~m}$ ) (Carozza et al., 2009). This cave is a rare example of a Bronze Age site, with both archaeological remains (ceramics and hearths) and rock art (incision, engraving, fingerings) preserved. The preservation of this site is exceptional as the cave entrance collapsed right after its last human occupation, 3300 years ago. Multiple traces of fire (reddened areas, ashes, charcoal) are visible in the cave galleries.

This study was carried out to contribute to the characterisation of the human occupation of the cave, and particularly the fire impact on the natural site (sediment and rock walls) was focused on. The intensity and the function of hearths were investigated from a multidisciplinary point of view. The objective of this article is to introduce a novel method for the thermal characterisation of hearths. For these purposes, thermoluminescence (TL) and magnetic susceptibility measurements were carried out to characterise the heating of the sediment forming the ground of the ancient fires.

\section{Materials and Methods}

\section{Thermoluminescence}

Thermoluminescence is usually used to date heated materials for chronological purposes (McKeever and Chen, 1997). In this study we extracted part of the usual TL dating protocol in Bordeaux and determined the paleotemperature of samples using the variation of the TL signal with differing ancient heating conditions (temperature and duration) (Lahaye et al., 2006; Roque et al., 2004; Valladas, 1981; Vieillevigne et al., 2007).

Thermoluminescence measurements were carried out with an automatic equipment that was designed and built in the Bordeaux laboratory. The main parts of this apparatus are a beta ${ }^{90} \mathrm{Sr}$ source used to simulate the natural irradiation, a heating chamber surmounted by optical filters, a PM tube (EMI 9813 QA) and associated electronics that record the luminescence signals as a function of temperature. The TL signals of the quartz grains extracted from sediments are recorded while heating from room temperature to $500^{\circ} \mathrm{C}$ at $4^{\circ} \mathrm{C} / \mathrm{s}$ under a neutral nitrogen atmosphere. The optical window selected ranged from 350 to $475 \mathrm{~nm}$, in accordance with the main luminescence spectrum of quartz. A chamber furnace (Eurotherm 2416CG, CARBOLITE) was used to prepare the thermal references by heating the pristine sedimentary material sampled in the cave according to a precisely designed heating cycle detailed further on.
Correspondence: Aurélie Brodard, Université de Bordeaux 3 - CNRS, IRAMAT-CRP2A, UMR 5060 , Maison de l'Archéologie, Esplanade des Antilles, 33607 Pessac, France.

Tel. +33.611.093571 - Fax: +33.557.124250 .

E-mail: aurelie.brodard@gmail.com

Key words: thermoluminescence, magnetic susceptibility, paleotemperature, hearth.

Acknowledgements: Université de Bordeaux 3 , University of La Rochelle, CNRS-INSHS and CNRS-INEE (SEEG), Service Régional de l'Archéologie d'Aquitaine, Mairie de SaintMartin-de-Fressengeas, Conseil Régional d'Aquitaine, Edmond et Marcelle Goineaud (owner of the site) are greatly acknowledged.

Citation: Brodard A, Guibert P, Lévêque F, Mathé V, Burens A, Carozza L, 2014. Thermal characterisation of Bronze Age hearths from the cave of Les Fraux (Dordogne, France) by thermoluminescence and magnetic susceptibility techniques. In: RH Tykot (ed.), Proceedings of the 38th International Symposium on Archaeometry - May $10^{\text {th }}-14^{\text {th }} 2010$, Tampa, Florida. Open Journal of Archaeometry 2:5457.

Presented at the $38^{\text {th }}$ International Symposium on Archaeometry - May $10^{\text {th }}-14^{\text {th }} 2010$, Tampa, Florida.

This work is licensed under a Creative Commons Attribution 3.0 License (by-nc 3.0).

(C) Copyright A. Brodard et al., 2014

Licensee PAGEPress, Italy

Open Journal of Archaeometry 2014; 2:5457

doi:10.4081/arc.2014.5457

\section{Magnetic susceptibility}

Magnetic susceptibility is indicative of the magnetisation potential of a material when a magnetic field is applied. Magnetic susceptibility measurements can be done in situ and quickly give indications on the magnetic mineral content. Numerous minerals contain iron (Cornell and Schwertmann, 2003) and contribute to the magnetic susceptibility. In descending order of magnetic susceptibility, there are magnetite, maghemite, hematite, goethite, lepidocrocite, etc.

Heating by fire generates mineralogical transformations, particularly among iron oxides. Transformation and destruction depend on the temperature attained. For example, by thermal dehydration lepidocrocite can transform into magnetite (Cudennec and Lecerf, 2005) implying an enhanced magnetic susceptibility.

Heated sediment contains more magnetic minerals, hence has higher values of magnetic susceptibility than unheated sediment: 
the higher the attained temperatures, the stronger the magnetic susceptibility.

Measurements of magnetic susceptibility in situ were done with a contact susceptometer: KT-9, Exploranium.

\section{Results and Discussion}

\section{Methodological overview}

On the site first, a map of magnetic susceptibility of the hearth was reconstructed by surface measurements in the fire area selected. This set of measurements allowed choosing the sampling locations more precisely in a subsequent step. A sample of unheated sediment was also taken out to create a thermal references.

Then, in laboratory, the quartz grains were extracted from the sediment samples and the TL signal was measured. The comparison of the TL signal between hearth samples and the thermal references allows determining the paleotemperature of each sample. Finally, combining the on-site magnetic susceptibility measurements and paleotemperature, we obtained a paleotemperature map of the entire hearth.

\section{Magnetic susceptibility mapping}

This study focused on the peculiar hearth presented in Figure 1. Firstly, a map of magnetic susceptibility (Figure 2) was constructed using a KT-9 susceptometer on a limited zone around the shaped hearth of the cave. The map shows three zones of high magnetic susceptibility corresponding to the most concentrated magnetic phases, which we can assume to be the most heated places.

\section{Sampling and quartz extraction}

Based on this, small samples (1-2 g) were extracted from the hearth (white crosses show samples locations, Figure 1). An additional sample of unheated sediment of the cave (same geological origin) was selected to obtain a thermal reference to be compared with samples of hearth sediment.

For TL measurements, quartz grains were extracted. After disaggregation of the sediment and sieving, grains sized between 200 and $500 \mu \mathrm{m}$ were chemically treated. Carbonate phases were removed using $\mathrm{HCl}$ (1 M) and organic matter by washing with hydrogen peroxide. An additional treatment by immersion in concentrated HF solution $(0.5 \mathrm{M})$ for one hour at room temperature was also performed to dissolve remaining clay materials and other minerals, such as feldspars. The aim of these chemical treatments is to obtain a sample solely consisting of quartz.

\section{Thermoluminescence signal of thermal references and samples of hearth}

Fourteen thermal references were processed in an electric oven according to a rigorously designed thermal protocol: a heating rate of $20^{\circ} \mathrm{C} / \mathrm{min}$ from room temperature to the maximum temperature programmed, then one hour at this temperature and subsequently a cooling rate of $5^{\circ} \mathrm{C} / \mathrm{min}$. The maximum temperature was varied from 200 to $650^{\circ} \mathrm{C}$, while keeping an unheated sample to compare with. These thermal parameters were chosen to correspond to heating rates and maximal temperatures in a real fire (Carrancho and Villalaín, 2008; Werts and Jarhen, 2007).
To compare the TL signal between the reference and hearth samples, it is necessary to simulate on references the irradiation received by hearth samples during the time elapsed since the archaeological fire. Therefore a $\beta$ irradiation and a preheating at $230^{\circ} \mathrm{C}$ were applied on reference materials. The evolution of the TL signal of the thermal reference samples as a function of the maximum temperature is shown on Figure 3 . To illustrate the procedure, Figure 4 displays the natural TL signal of two different samples in association with their best-fit references curves.

\section{Determination of paleotemperature}

To estimate the sample paleotemperature the TL signal of reference samples and those of hearth samples were compared based on the shape of the respective TL curves. Initially, a visual comparison was made, followed by studying the relative variance of the ratio of intensity between the natural signal of the sample examined with the regenerated signal of the reference samples. Finally, a hierarchic classification of all sample's curves (using STATISTICA, Ward method) was obtained based on the mutual comparison of the TL curves. Four groups are identified: i) unheated reference samples and one sample heated at $200^{\circ} \mathrm{C}$; ii) reference samples heated at $250^{\circ} \mathrm{C}$; iii) reference samples heated from $300^{\circ} \mathrm{C}$ to $450^{\circ} \mathrm{C}$; and iv) reference samples heated from 500 to $650^{\circ} \mathrm{C}$. Two examples of a TL signal and the comparison with reference samples are presented in Figure 4. The hierarchic classification confirms the visual interpretation of the curves, while sample number 1 seems unheated and number 9 appears to be heated at $375^{\circ} \mathrm{C}$.

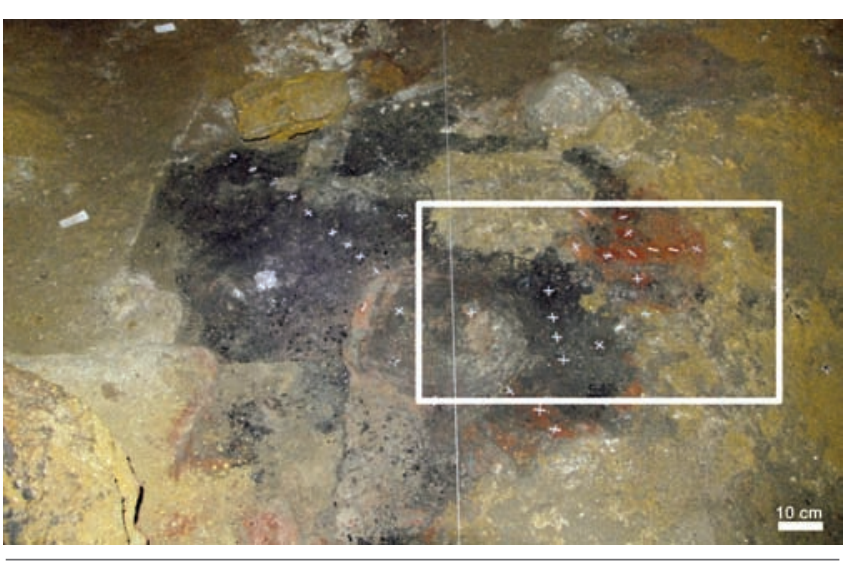

Figure 1. Hearth with white crosses showing sample locations. The rectangle represents the area of the magnetic susceptibility mapping.

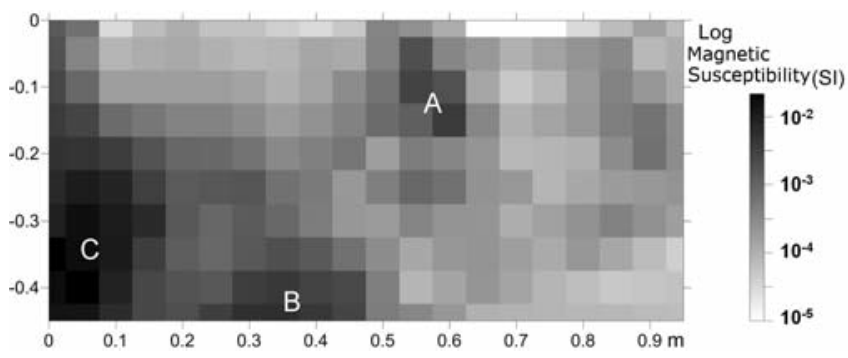

Figure 2. Map of magnetic susceptibility showing three zones of high magnetic susceptibility $(A, B, C)$ corresponding to the most concentrated magnetic phases. 


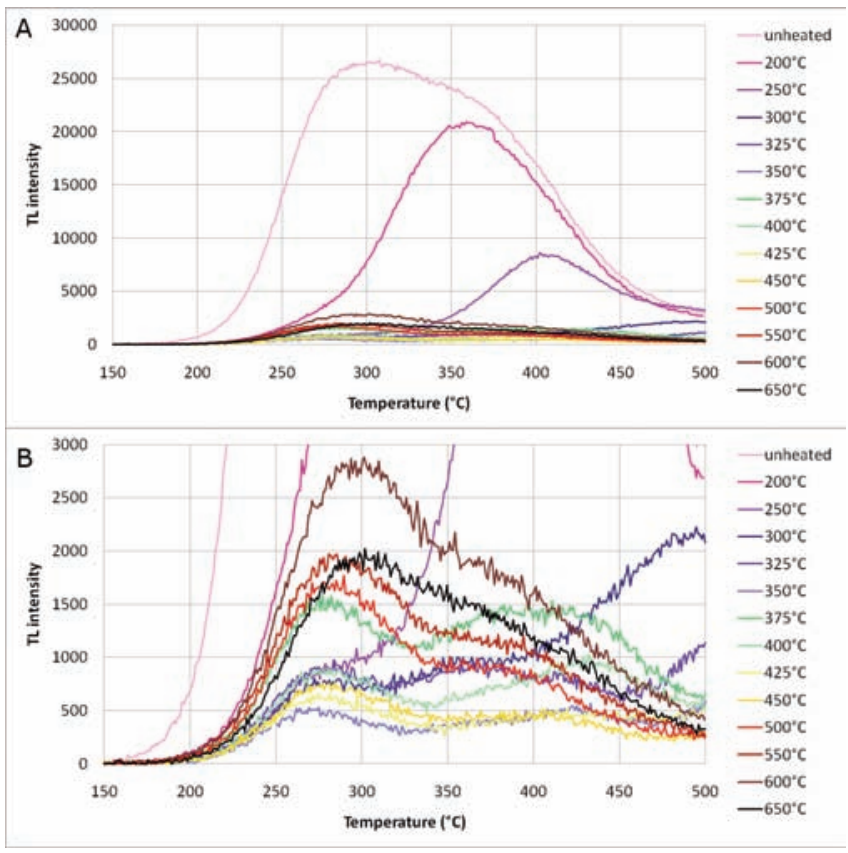

Figure 3. A) Evolution of the thermoluminescence signal of the thermal reference samples as a function of the maximum temperature. B) is an enlargement for low thermoluminescence intensity.

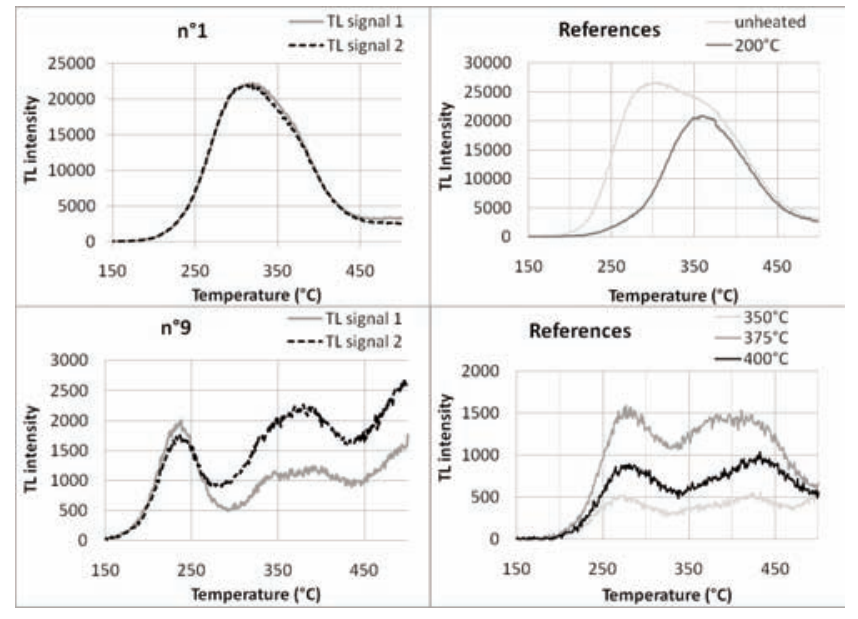

Figure 4. Natural thermoluminescence signal of two different samples in association with their best-fit references curves.

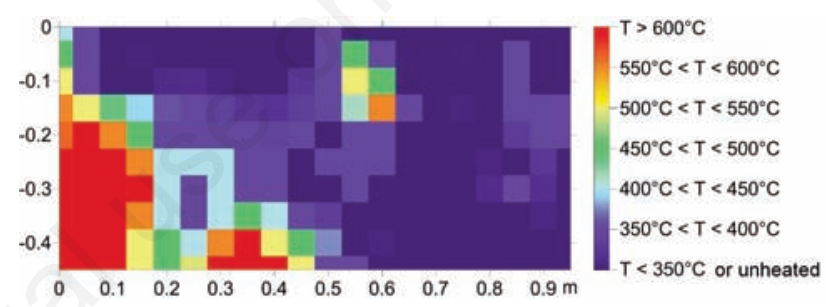

Figure 5. Paleotemperature map of the study area.
Table 1 summarises the paleotemperature results of each sample.

\section{Combination of thermolumines-} cence and magnetic susceptibility

Combining the paleotemperatures found by TL with the values of magnetic susceptibility allows us to estimate the magnetic susceptibility as a function of paleotemperature, and therefore reconstruct a paleotemperature map of the study area (Figure 5). The three heated places are clearly visible, but additional temperature information obtained from this analysis is depicted.

\section{Conclusions}

The integration of TL and magnetic susceptibility measurements on burnt sediments permits us to map the paleotemperature attained by sediments over larger areas. This work presents a novel methodology to quantitatively study ancient fires. The temperature reached by the topmost sediment is a first indication of the intensity of ancient fires. To
Table 1. Summary of the paleotemperature results of each sample.

\begin{tabular}{lccc} 
Sample no. & Temperature $\left({ }^{\circ} \mathrm{C}\right)$ & Sample no. & Temperature $\left({ }^{\circ} \mathrm{C}\right)$ \\
1 & 25 & 16 & 250 \\
2 & 350 & 17 & 250 \\
\hline 3 & 425 & 22 & 450 \\
4 & 325 & 23 & 325 \\
\hline 5 & 425 & 24 & $>300$ \\
6 & 550 & 25 & $?$ \\
\hline 7 & 600 & 26 & 600 \\
8 & 425 & 27 & 450 \\
\hline 9 & 375 & 28 & $>300$ \\
10 & 25 & 29 & 600 \\
\hline 11 & 400 & 30 & 600 \\
12 & 25 & 31 & $?$ \\
\hline 13 & 600 & 32 & 250 \\
14 & 25 & 33 & 200 \\
\hline 15 & 25 & 34 & 200 \\
\hline
\end{tabular}


widen the scope of this study, experimental fires will be set up under environmental conditions material close to those encountered in the cave of Les Fraux. These experiments will enable validation of the results of this study's temperature determination and will enable modelling fires by their intensity, issued energy (light and heat) and quantity of wood consumed in a given duration.

\section{References}

Carozza L, Burens A, Billaud Y, Ferullo 0, Bourrillon R, Petrognani S, Fritz C, Tosello G, Goineaud E, Saint-Martin-deFressengeas M, 2009. [Grotte des Fraux. Bilan scientifique de la région Aquitaine 2007]. [Book in French]. DRAC Aquitaine - SRA, Ministère de la Culture et de la Communication ed., Paris, France.
Carrancho A, Villalaín JJ, 2008. [Estudio experimental de las transformaciones en la mineralogía magnética en fuegos prehistóricos y sus implicaciones en Arqueomagnetismo]. [Article in Spanish]. Geotemas 10:1-4.

Cornell RM, Schwertmann U, 2003. The iron oxides - structures, properties, reactions, occurences and uses. Wiley-VCH, Weinheim Germany.

Cudennec Y, Lecerf A, 2005. Topotactic transformations of goethite and lepidocrocite into hematite and maghemite. Solid State Sci 7:520-9.

Lahaye C, Godfrey-Smith DI, Guibert P, Bechtel F, 2006. Equivalent thermal history (HE) of ferruginous sandstones based on the thermal activation characteristics of quartz. Radiat Meas 41:9951000.

McKeever SWS, Chen R, 1997. Luminescence models. Radiat Meas 27:625-61.
Roque C, Guibert P, Duttine M, Vartanian E, Chapoulie R, Bechtel F, 2004. Dependence of luminescence characteristics of irradiated quartz with the thermal treatment and consequences for TL dating. Geochronometria 23:1-8.

Valladas H, 1981. [Thermoluminescence de grès de foyers préhistoriques: estimation de leur température de chauffe]. [Article in French]. Archaeometry 23:221-9.

Vieillevigne E, Guibert P, Bechtel F, 2007. Luminescence chronology of the medieval citadel of Termez, Uzbekistan: TL dating of bricks masonries. J Archaeol Sci 34:1402-16.

Werts SP, Jarhen AH, 2007. Estimation of temperature beneath archaeological campfires using carbon stable isotope composition of soil organic matter. J Archaeol Sci 34:850-7. 